\title{
Application of the Southwell plot method to the inspection and testing of buried flexible pipes
}

\author{
A. J. VALSANGKAR, A. M. BRITTO \& M. J. GUNN
}

\section{Dr T. L. L. Orr, Trinity College, Dublin}

The Southwell plot method for estimating the buckling of a buried flexible pipe is based on the measurement of the growth of an elastic instability. As the Authors point out, in the case of my test $\mathrm{LD}^{12}$ it would have been more appropriate to use the change of diameter between the shoulder where the buckle developed and the opposite haunch than to use the change of vertical diameter of the pipe. In fact in tests LD and LE strain gauge pairs were bonded to the inside and outside surfaces of the pipes close to where buckling occurred. Strain measurements from these gauges allow the bending moments in the pipes to be calculated and, if these data are presented in the form of a Southwell plot, predictions for the buckling loads may be obtained.

42. The Southwell plot method is based on the fact that, for small-deflexion theory, displacements and strains tend to become very large as the applied loading approaches the buckling load. Therefore, using bending moments $M$ calculated from the measured strains, equation (1) may be rewritten as

$$
\frac{M}{P}=\frac{M}{P_{1}}+\frac{M_{1}}{P_{1}}
$$

where the constant $M_{1}$ is proportional to $\delta_{1}$. If $M / P$ is plotted against $M$ a straight line is obtained with slope of $1 / P_{1}$ and intercept $-M_{1}$ on the $M$ axis. Fig. 15 shows the Southwell plots for tests LE and LD drawn using bending moments calculated from the strain gauge data. The loading in these tests is the difference between the surface pressure and the pressure in the pipe, i.e. $P=P_{3}-P_{t}$. In the case of test LD the plot using the bending moments measured at the pipe shoulder close to where buckling occurred is linear over a greater range of loading than the plot in Fig. 7 using the changes of vertical diameter.

43. The buckling loads $\boldsymbol{P}_{\mathrm{Ed}}$ and $\boldsymbol{P}_{\mathrm{Em}}$ predicted by the Southwell plots using changes of diameter and bending moment data respectively are given in Table 6 . The Southwell plots using the bending moment data predict buckling loads much closer to the actual collapse loads than do the Southwell plots using the changes of pipe diameter. In the case of test $\mathrm{LD} P_{\mathrm{Em}} / P_{\mathrm{f}}=1 \cdot 20$, whereas $P_{\mathrm{Ed}} / \boldsymbol{P}_{\mathrm{f}}=1.77$. These results show that the best predictions are obtained when the data for the Southwell plot are measured as close as possible to the point where buckling eventually

Paper published: Proc. Instn Civ. Engrs, Part 2, 1981, 71, Mar., 63-82. 


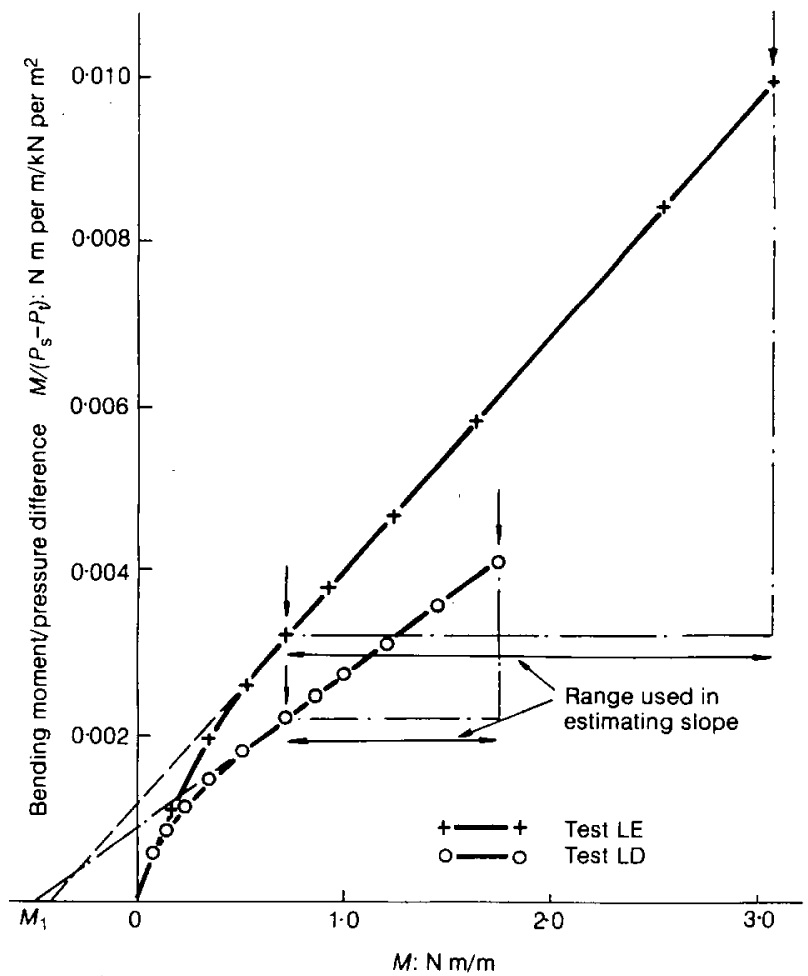

Fig. 15. Southwell plot using measured bending moments

occurs. However, as the exact position of the buckle cannot be predicted with certainty, ideally initial measurements should be recorded at a large number of points around the pipe circumference. This is a practical disadvantage of the Southwell plot method.

44. The Authors refer to $\delta_{1}$, the intercept of the Southwell plot on the deflexion axis, as the initial imperfection. They define this term as a general property of a particular pipe that can be determined from a Southwell plot. However, if the predicted buckling load depends on where the measurements are recorded, the value of the initial imperfection will also depend on the data used to construct the Southwell plot. Table 6 shows that the values of $M_{1}$, which are proportional to the initial imperfections, are in closer agreement than the values of $\delta_{1}$. Thus $\delta_{1}$ cannot be a pipe property but is a function of how close the measurements are recorded to the position of the buckle as well as being a function of the initial out of roundness of the pipe.

45. In $\S 21$ the Authors state that the mode of buckling for the model pipes used in my tests was similar to that shown in Fig. 11(a). In fact the pipes in my tests, although collapsing by buckling at or near the crown, did not fail as a result of crown collapse but because of a shorter wavelength buckle. The outlines of the buckled pipes after collapse in tests LE and LD are shown in Fig. 16. The collapse 


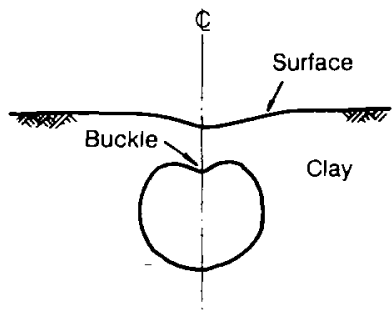

(a)

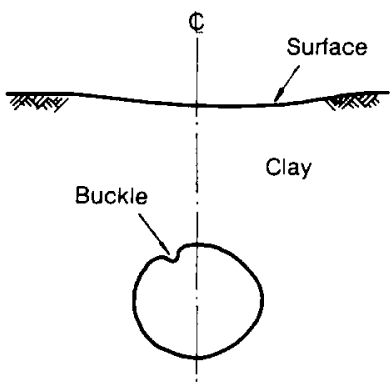

(b)

Fig. 16. Outlines of buckled pipes: (a) test LE; (b) test LD

mode in these cases is similar to that shown in Fig. 11(b) for a very flexible pipe.

46. To determine whether a pipe is flexible or very flexible and hence to predict how and where a pipe will buckle, it is not sufficient to consider only the effective stiffness $E I / R^{3}$ of the pipe. The stiffness of the surrounding soil and the ratio of the pipe and soil stiffnesses must also be taken into account. Another parameter affecting the buckling of a pipe is the depth of cover $C$. This is shown by the buckled forms of the pipes (see Fig. 16). The support provided by the soil or backfill around the crown will be less for pipes at shallow depths than for pipes buried more deeply in the same material. Hence the mode of buckling for flexible pipes and the position where buckling occurs is influenced by the effective stiffness of the pipe, the relative stiffness of the pipe with respect to the surrounding soil and the depth of cover. All these factors are important in a practical situation and should be considered particularly when applying the method to the inspection and testing of flexible pipes at shallow depths in urban areas.

\section{Dr Valsangkar, Dr Britto and Mr Gunn}

We agree that it is possible (and perhaps advantageous) to use bending moments rather than deflexions in constructing a Southwell plot for a loading test on a flexible buried pipe. In practice the choice would probably be based on the availability of suitable instrumentation.

48. We agree that the initial imperfection deduced from a Southwell plot will depend on the position on the pipe at which measurements of strains or deflexions

Table 6. Southwell plot results

\begin{tabular}{l|c|c|c|c|c|c|c}
\hline Test & $\begin{array}{c}P_{\mathrm{Ed}} \\
\text { buckling load } \\
\text { predicted } \\
\text { using diameter } \\
\text { change data, } \\
\mathrm{kN} / \mathrm{m}^{2}\end{array}$ & $\begin{array}{c}P_{\text {Em }} \\
\text { buckling load } \\
\text { predicted } \\
\text { using bending } \\
\text { moment data, } \\
\mathrm{kN} / \mathrm{m}^{2}\end{array}$ & $\begin{array}{c}P_{\mathrm{f}} \\
\text { observed } \\
\text { collapse } \\
\text { load, } \\
\mathrm{kN} / \mathrm{m}^{2}\end{array}$ & $\frac{P_{\mathrm{Ed}}}{P_{\mathrm{f}}}$ & $\frac{P_{\mathrm{Em}}}{P_{\mathrm{f}}}$ & $\begin{array}{c}\delta_{1}, \\
\mathrm{~mm}\end{array}$ & $\begin{array}{c}M_{1}, \\
\mathrm{Nm} / \mathrm{m}\end{array}$ \\
\hline LE & 400 & 349 & 314 & 1.27 & 1.11 & 0.70 & 0.40 \\
\hline LD & 769 & 521 & 435 & 1.77 & 1.20 & 2.40 & 6.46 \\
\hline
\end{tabular}


are made. From analogy with the behaviour of a strut it can be expected that the further the point of measurement is from the centre of the eventual buckle, the smaller the value of initial imperfection will be. However, the predicted buckling load will not be influenced in the same way and can be regarded with more confidence (as long as a linear Southwell plot is established). This means that some care should be exercised in interpreting the effect of such initial imperfections on load carrying capacity in the manner suggested by Fig. 10 .

49. The statement that 'the initial imperfection is a general property of a pipe' was made to emphasize the fact that the magnitude of the initial imperfection cannot be assessed by careful measurement of the out of roundness of the pipe before the pipe is loaded. The size of initial imperfection deduced from a Southwell plot will depend on a number of factors, including the initial out of roundness, the manner in which the load is applied, the support provided by the soil and the distance of the point of measurement from the eventual buckle.

50. In the Paper the distinction between the two types of buckling was simply stated based on the pipe stiffness. For pipes buried at shallow depths and in the range of stiffness considered in the Paper a long wavelength buckle is the probable mode of failure providing the loading surface is not wider than the diameter of the pipe. In tests carried out in the laboratory where surface pressure is applied, the situation is similar to that of field pipes buried at great depths. ${ }^{19}$ This effectively reduces the buckling wavelength. In the case where the pipe is very flexible the failure is more likely by a local creasing (a very short wavelength buckle), shown exaggerated in Fig. 11(b). In our opinion Dr Orr's test LE would come under the category shown in Fig. 11(a). The short wavelength buckle shown in Fig. 11(b) is of a category where it is difficult to monitor the growth of an imperfection to eventual buckling failure. The fact that Dr Orr managed to obtain a Southwell plot for his test LD precludes this from the category in Fig. 11(b). It is interesting that Dr Orr was able to construct a linear Southwell plot from strain measurements made at $45^{\circ}$ intervals around the perimeter of the pipe. Whatever assessment is made of the nature of the buckles in Dr Orr's tests, it is difficult to escape the conclusion that the use of the Southwell plot method was successful.

51. We agree with Dr Orr that there are other factors which will influence the mode of failure of a buried flexible pipe apart from its effective stiffness. However, we hope that the complexity of the problem will not discourage engineers from using what is essentially a very simple technique in practical situations. The method has recently been applied to the interpretation of the load-deformation response of unreinforced concrete pipes in gravel backfill. ${ }^{20}$ Although there was no question of elastic instability or non-linear geometric effects in this case, linear Southwell plots were obtained.

52. The non-linearity in this system is clearly due to behaviour of the gravel and not the pipe. Thus the method has the potential for being applied to the loading of any system that gives a non-linear response. If the load-deformation behaviour follows a hyperbolic relation (tending to a horizontal asymptote) then the Southwell plot will be linear and an estimate of the ultimate load can be obtained.

\section{References}

19. VAlSANGKAR A. J. and BritTo A. M. The validity of ring compression theory in the design of flexible buried pipes. Transport and Road Research Laboratory, Crowthorne, 1978, Supplementary report 440 . 
20. Trott J. J. and Stevens J. B. The load carrying capacity of cracked rigid pipes-a preliminary study. Transport and Road Research Laboratory, Crowthorne, 1980, Supplementary report 534 .

\section{Corrigendum}

In the key of Fig. 10 the symbols referring to the data from English and Orr should be transposed. 